\title{
Contemporary incidence and risk factors for carotid artery disease in patients referred for coronary artery bypass surgery
}

\author{
Kelly M Wanamaker ${ }^{1}$, Robert J Moraca ${ }^{1,2^{*}}$, Diane Nitzberg ${ }^{1}$ and George J Magovern $\mathrm{Jr}^{1}$
}

\begin{abstract}
Background: In the past decade, there has been an increase in the amount of patients with medical co-morbidities referred for coronary artery bypass surgery (CABG). Significant carotid artery disease in patients undergoing $C A B G$ procedures increases the risk of neurological complications. We review the results of routine carotid screening in patients undergoing CABG to determine the contemporary incidence and risk factors for carotid artery disease.
\end{abstract}

Methods: Between 2008 through 2010, 673 patients were referred for isolated coronary artery bypass surgery at a single institution. Patients were identified through a systematic review of The Department of Cardiothoracic Surgery Society of Thoracic Surgery Outcomes Database. A retrospective analysis of prospectively collected demographic, clinical data and outcomes were performed. All patients with screening preoperative carotid duplex were reviewed. We defined the degree of carotid disease as: none to mild stenosis $(<50 \%)$, moderate stenosis $(50-69 \%)$, severe stenosis (70-99\%). Multivariate analysis was performed to identify risk factors.

Results: 559 (83\%) patients underwent screening preoperative carotid ultrasonography prior to CABG. The incidence of carotid artery disease (>50\% stenosis) was 36\% with $18 \%$ unilateral moderate disease, $10 \%$ bilateral moderate and $8 \%$ severe disease. Risk factors associated with carotid artery disease included: advanced age, renal failure, previous stroke, peripheral vascular disease, left main coronary artery disease, and previous myocardial infarction.

Conclusions: There is a significant incidence of carotid artery stenosis in patients referred for CABG. Routine screening will identify patients with carotid artery disease and may reduce the risk of postoperative stroke.

Keywords: Coronary artery bypass surgery, Carotid artery stenosis

\section{Background}

Stroke is a deleterious complication of coronary artery bypass grafting (CABG) with an incidence of $1.2 \%$ [1]. Despite improvements in anesthesia and surgical techniques, stroke remains a devastating neurologic complication of myocardial revascularization and is one of the primary concerns when assessing a patient's cardiopulmonary bypass candidacy.

The etiology of a cerebrovascular accident after CABG is multifactorial making it difficult to determine which mechanism is implicated in a particular event. Calcific

\footnotetext{
* Correspondence: rmoraca@wpahs.org

'Department of Cardiovascular and Thoracic Surgery, Allegheny General Hospital, Pittsburgh, PA

${ }^{2}$ Department of Cardiovascular and Thoracic Surgery, Allegheny General Hospital, 320 East. North Avenue, Pittsburgh, PA
}

debris from a diseased valve, macroemboli of cardiac origin, introduction of air during the procedure, hypoperfusion arising from a severely stenotic carotid artery or embolization from an ulcerated plaque have all been described [2].

Several studies have shown that the existence of carotid artery stenosis (CAS) in subjects undergoing cardiopulmonary bypass procedures increases the risk of significant neurological deficits [3-9]. Intraoperative hemodynamic instability and anemia with resultant cerebral hypoperfusion particularly in patients with extracranial carotid disease may account for a significant number of intraoperative events. Furthermore, studies have shown a direct link between degree of carotid artery stenosis and risk of ipsilateral stroke [10]. The 
inherently poor postoperative course of patients who develop stroke after CABG underlines the need for timely recognition and modification of factors that predispose to stroke.

The objective of our study was to investigate the contemporary incidence of CAS in patients undergoing isolated $\mathrm{CABG}$ and to determine risk factors related to carotid stenosis.

\section{Methods}

\section{Study population}

Between January 2008 and January 2010, 673 consecutive patients underwent isolated CABG at Allegheny General Hospital. Patients were identified through a systematic review of The Department of Cardiothoracic Surgery Society of Thoracic Surgery Outcomes Database. The Institutional Review Board (IRB) approved the study. A retrospective analysis of prospectively collected demographic and clinical data and clinical outcomes was performed.

\section{Carotid artery evaluation}

559 (83.1\%) patients underwent bilateral carotid duplex ultrasonography to analyze for the presence and extent of stenosis in their cerebrovasculature. Patients who did not receive preoperative carotid screening were those with either ongoing angina, hemodynamic instability in need of urgent coronary revascularization, or physician preference. Duplex measurements of peak systolic velocity (PSV) of the internal carotid artery (ICA) were recorded, and the ratio of these velocities in the internal and common carotid arteries (ICA: CCA) was calculated (Table 1). The criteria determined for detection of $50 \%$ or greater stenosis were as follows: peak systolic velocity of the internal carotid artery greater than $125 \mathrm{~cm} / \mathrm{s}$ and ratio of peak systolic velocity of the internal carotid artery to peak systolic velocity of the common carotid artery greater than 2. Our definition of degree of stenosis paralleled that of radiologic guidelines [11], none to mild stenosis $(<50 \%)$ is defined as PSV $<125 \mathrm{~cm} / \mathrm{sec}$ and an ICA:CCA ratio of $<2.0$, moderate stenosis $(50-69 \%)$ as a PSV of 125 to $229 \mathrm{~cm} / \mathrm{sec}$ or an ICA:CCA ratio between 2.0 and 3.9, and severe stenosis (70-99\%) as a PSV of $\geq 230 \mathrm{~cm} / \mathrm{sec}$ or an ICA:CCA ratio $\geq 4.0$ and a occluded carotid artery is defined as having a PSV and an ICA: CCA ratio of 0 . We defined significant and severe carotid artery stenosis as $>50 \%$ and $>70 \%$ respectively.

Table 1 Carotid artery stenosis definition and degree of severity

\begin{tabular}{llll}
\hline $\begin{array}{l}\text { Duplex US } \\
\text { Measurement }\end{array}$ & Mild $<50 \%$ & Moderate 50-69\% & Severe 70-99\% \\
\hline PSV $_{\text {ICA }}(\mathrm{mm} / \mathrm{sec})$ & $<125$ & $125-229$ & $>230$ \\
\hline $\mathrm{PSV}_{\mathrm{ICA}} / \mathrm{PSV}$ & & $2.0-3.9$ & $>4.0$ \\
\hline
\end{tabular}

\section{Measured risk factors}

The following clinical and demographic risk factors were analyzed for incidence and correlation with carotid artery disease: age, sex, congestive heart failure, hypertension, chronic obstructive pulmonary disease (COPD), history of stroke, peripheral vascular disease (PVD), hemodialysis dependent chronic kidney disease (CKD), previous myocardial infarction, body mass index, history of smoking, familial history of CAD, hyperlipidemia, diabetes mellitus, previous percutaneous coronary intervention, hyperlipidemia, left main trunk disease (LMT) and the number of coronary bypasses were examined [8,12-15].

\section{Statistical analysis}

Our prospectively collected database was interrogated to analyze preoperative patient characteristics, risk factors and degree of carotid stenosis. They were compared by univariate analysis using Statistical Analysis Systems (SAS Institute, Cary, North Carolina). A p value $<0.05$ was considered significant.

\section{Results}

Significant carotid artery stenosis $(>50 \%)$ was found in 200 of $559(35.7 \%)$ of our patient population (24.3\% women, mean age 67). In the 559 patients who had preoperative carotid duplex ultrasound, as listed in Table 2, $64 \%$ had mild to no stenosis and $\mathbf{3 6} \%$ had significant carotid artery stenosis $(>50 \%)$.

The clinical and demographic characteristics of patients with and without significant CAS are compared in Table 3. Logistic multiple regression analysis revealed the following independent risk factors for significant CAS: advanced age, female gender, hypertension, history of cerebrovascular accidents (CVA), dialysis, and peripheral vascular disease. Additionally, left main disease may offer some insight to the severity of atherosclerotic disease. Variables such as smoking, hyperlipidemia, and diabetes were not statistically significant.

Patients with severe carotid artery stenosis $>70 \%$ were compared to those without significant disease in Table 4. Congestive heart failure (CHF), history of myocardial infarction, and recent or remote smoking history were also found to be significant variables. Those factors associated

Table 2 Incidence of carotid artery disease

\begin{tabular}{ll}
\hline Degree of Stenosis & CABG ( $\mathbf{n = 5 5 9 )}$ \\
\hline Mild/None & $359(64 \%)$ \\
\hline Stenosis $>50 \%$ & $200(36 \%)$ \\
\hline Unilateral Moderate & $98(18 \%)$ \\
\hline Bilateral Moderate & $53(9.4 \%)$ \\
\hline Unilateral Severe/Occluded & $20(3.5 \%)$ \\
\hline Bilateral Moderate \& Severe & $15(2.6 \%)$ \\
\hline Bilateral Severe & $14(2.5 \%)$ \\
\hline
\end{tabular}


Table 3 Demographic and clinical characteristics of Patients with Significant Carotid Stenosis ( $>50 \%$ )

\begin{tabular}{lllll}
\hline & $\begin{array}{l}\text { All } \\
(\boldsymbol{n}=559)\end{array}$ & $\begin{array}{l}\text { No CAS } \\
(\boldsymbol{n}=\mathbf{3 5 9})\end{array}$ & $\begin{array}{l}\text { CAS } \\
(\boldsymbol{n}=\mathbf{2 0 0})\end{array}$ & $\boldsymbol{p}$ value \\
\hline Mean Age (years) & 67 & 65.5 & 68.6 & $\mathbf{0 . 0 0 3}$ \\
\hline Women & $24 \%$ & $24 \%$ & $32 \%$ & $\mathbf{0 . 0 0 4 6}$ \\
\hline CHF & $13 \%$ & $12 \%$ & $17 \%$ & 0.12 \\
\hline Hypertension & $94 \%$ & $94 \%$ & $92 \%$ & $\mathbf{0 . 0 4}$ \\
\hline COPD & $23 \%$ & $21 \%$ & $27 \%$ & 0.1 \\
\hline CVA & $5.4 \%$ & $3.8 \%$ & $8 \%$ & $\mathbf{0 . 0 2}$ \\
\hline PVD & $15 \%$ & $10 \%$ & $23 \%$ & $\mathbf{0 . 0 0 0 1}$ \\
\hline CKD (Dialysis) & $13 \%$ & $9 \%$ & $21 \%$ & $\mathbf{0 . 0 0 0 1}$ \\
\hline History of Ml & $45 \%$ & $44 \%$ & $47 \%$ & 0.47 \\
\hline BMI (Mean) & 30 & 30.5 & 30.1 & 0.4 \\
\hline History of Smoking & $59 \%$ & $58 \%$ & $62 \%$ & 0.9 \\
\hline Family History of Coronary Disease & $33 \%$ & $35 \%$ & $28 \%$ & 0.09 \\
\hline Hyperlipidemia & $85 \%$ & $84 \%$ & $86 \%$ & 0.6 \\
\hline Diabetes & $36 \%$ & $35 \%$ & $40 \%$ & 0.7 \\
\hline Previous PTCA & $27 \%$ & $27 \%$ & $26 \%$ & 1.0 \\
\hline Antilipid Use & $71 \%$ & $69 \%$ & $70 \%$ & 0.9 \\
\hline Left main Trunk & $31 \%$ & $27 \%$ & $37 \%$ & $\mathbf{0 . 0 1 6}$ \\
\hline Number of Bypass & 2.52 & 2.53 & 2.52 & 0.8 \\
\hline CAS C & & & & \\
\hline
\end{tabular}

CAS=Carotid artery stenosis $>50 \%$.

Severe CAS $=$ Carotid artery stenosis $>70 \%$ unilateral or bilateral.

with significant stenosis but not severe stenosis were female gender and hypertension.

\section{Discussion}

Incidence of carotid artery stenosis in CABG patients

It has been shown that significant CAS is common in patients undergoing CABG [13]. In studies which examined all patients undergoing CABG, CAS $\geq 50 \%$ has been detected in nearly one in three patients [16]. In our study the incidence of significant carotid artery stenosis in patients referred for isolated CABG is 36\%. This is consistent with previous studies which have reported a prevalence of $6.1 \%-31.7 \%$ in CABG patients depending upon definitions of the degree of stenosis and methods of screening $[4,13,16-19]$. For severe carotid stenosis (>75\%), the prevalence has been reported to be $4.1 \%$ $13.3 \%[8,9,12,16]$ which also remains consistent with our findings of $>70 \%$ stenosis in $8.8 \%$ of patients.

\section{Risk factors for carotid stenosis}

With the data provided by these studies, univariate analysis identified advanced age, female gender, hypertension, prior stroke, dialysis, peripheral vascular disease (PVD), and left main disease as independent risk factors for significant carotid stenosis. Except for congestive heart failure (CHF), prior myocardial infarction (MI), and smoking predictors for severe CAS (>70\%) were
Table 4 Demographic and clinical characteristics of Patients with Severe Carotid Stenosis ( $>70 \%$ )

\begin{tabular}{llll}
\hline No CAS & $\begin{array}{l}\text { Severe CAS only } \\
(\mathbf{n = 3 5 9 )}\end{array}$ & $\begin{array}{l}\boldsymbol{p} \text { value } \\
(\mathbf{n = 4 9 )}\end{array}$ \\
\hline Age & 65.5 & 69.2 & $\mathbf{0 . 0 1}$ \\
\hline Women & $24 \%$ & $24 \%$ & 1.0 \\
\hline CHF & $12 \%$ & $29 \%$ & $\mathbf{0 . 0 0 3}$ \\
\hline Hypertension & $94 \%$ & $92 \%$ & 0.5 \\
\hline COPD & $21 \%$ & $30 \%$ & 0.14 \\
\hline CVA & $3.8 \%$ & $10 \%$ & $\mathbf{0 . 0 5}$ \\
\hline PVD & $10 \%$ & $33 \%$ & $\mathbf{0 . 0 0 0 1}$ \\
\hline CKD (Dialysis) & $9 \%$ & $22 \%$ & $\mathbf{0 . 0 1}$ \\
\hline History of MI & $44 \%$ & $61 \%$ & $\mathbf{0 . 0 2}$ \\
\hline BMl (Mean) & 30.5 & 31.1 & 0.5 \\
\hline History of Smoking & $58 \%$ & $75 \%$ & $\mathbf{0 . 0 1 9}$ \\
\hline Family History of Coronary Disease & $35 \%$ & $25 \%$ & 0.15 \\
\hline Hyperlipidemia & $84 \%$ & $90 \%$ & 0.39 \\
\hline Diabetes & $35 \%$ & $42 \%$ & 0.34 \\
\hline Previous PTCA & $27 \%$ & $22 \%$ & 0.6 \\
\hline Antilipid Use & $69 \%$ & $82 \%$ & 0.09 \\
\hline Left main Trunk & $27 \%$ & $53 \%$ & $\mathbf{0 . 0 0 0 4}$ \\
\hline Number of Bypass & 2.53 & 2.65 & 0.3 \\
\hline CAs Car & & & \\
\hline
\end{tabular}

CAS $=$ Carotid artery stenosis $>50 \%$.

Severe CAS $=$ Carotid artery stenosis $>70 \%$ unilateral or bilateral .

similar. These variables have been considered positive predictors in the genesis of atherosclerotic disease [20].

In a study by Mahmoudi and colleagues in 2011, carotid duplex ultrasound was performed on 878 patients prior to isolated CABG and they found that $13 \%$ had a carotid stenosis greater than 75\% [16]. Significant predictors for CAS were age $>69$ and PVD. Unlike our study, CHF, prior MI and tobacco abuse were not statistically significant.

Peripheral vascular disease, end stage kidney disease, advanced age, and prior stroke have been reported by other investigators as co-morbidities associated with CAS [9,12-14]. Our study similarly showed that they are the strongest predictors of CAS.

In 2010, Drohomirecka, et al. evaluated 682 patients using duplex ultrasound and found that 123 (18\%) had carotid stenosis greater than $50 \%$ and 29 (4.5\%) with severe CAS [13]. Predictors of significant carotid artery disease were history of cerebrovascular accidents, PVD, unstable angina, and older age. The predictors of severe stenosis (at least one carotid artery $\geq 70 \%$ ) were a history of stroke, PVD, and presence of left main disease.

Female gender has not been found to be a predictive factor for carotid stenosis in CABG patients; however, women undergoing $C A B G$ are at greater risk for major complications than men because of the comorbid conditions that are associated with the later age at which 
women present for coronary surgery and not because of gender [14]. In our study, the incidence of carotid stenosis $>50 \%$ in female patients was statistically different $(\mathrm{p}=0.0046)$ when compared to no CAS. Similarly, Durand et al. [9] and D'Agostino et al. [17] identified female gender, age $>65$ years, PVD, prior CVA, left main coronary disease, and hypertension as risk factors for significant carotid stenosis.

Advanced age is shown to be an independent risk factor for stroke in CABG, mainly among octogenarians [3]. Age is also an important risk factor for carotid artery disease $[8,9,13,14,16]$. One analysis of 1,068 patients showed $167(15.6 \%)$ with carotid artery stenosis $>50 \%$. The prevalence of stenosis in that group increased with age. CABG patients aged $<60$ years had a $4 \%$ prevalence, rising to $11 \%$ in patients $>60$ and $15 \%$ in those aged $>70$ [21].

Peripheral vascular disease has been reported by other investigators as a comorbidity associated with CAS $[9,13,14,19,21]$. Salasidis et al. [8] found a history of peripheral vascular disease in $81(20.9 \%)$ of 387 patients scheduled for nonemergent CABG; and among these 81 subjects, $26 \%(\mathrm{n}=21)$ had significant carotid stenosis.

The aforementioned clinical parameters may indicate a need for preoperative carotid ultrasound examination in patients undergoing isolated coronary revascularization. Patients with concomitant cerebrovascular and coronary artery disease represent a subset with advanced atherosclerosis in which other areas of the vascular system are involved. The incidence of carotid stenosis in patients with coronary artery disease is high which can translate to an increased risk of perioperative stroke. We found several demographic and clinical risk factors that are markers for atherosclerosis which may indicate the need for preoperative screening for CAS in patients undergoing isolated CABG.

\section{Limitations of the study}

The study was a retrospective review of medical records. Some patients undergoing urgent surgery were not included in the study due to lack of ultrasonographic examination.

\section{Conclusions}

There is a significant incidence of carotid artery stenosis in patients referred for CABG. Routine screening will identify patients with carotid artery disease and may reduce the risk of postoperative stroke.

\section{Competing interests}

The authors declare that they have no competing interests.

\section{Authors' contributions}

KMW and RJM wrote the manuscript, statistical analysis DN performed the data collection, GJM performed editorial oversight and assisted with statistical analysis. All authors read and approved the final manuscript.
Received: 28 April 2012 Accepted: 27 June 2012

Published: 28 August 2012

\section{References}

1. The Society of Thoracic Surgeons National Database; 2011. http://www.sts.org/national-database.

2. Likosky DS, Marrin CA, Caplan LR, et al: Determination of Etiologic Mechanisms of Strokes Secondary to Coronary Artery Bypass Graft Surgery. Stroke 2003, 34:2830-2834.

3. Stamou SC, Hill PC, Dangas G, et al: Stroke after coronary artery bypass: incidence, predictors, and clinical outcome. Stroke 2001, 32:1508-1513.

4. Naylor AR, Mehta Z, Rothwell PM, et al: Carotid artery disease and stroke during coronary artery bypass: a critical review of the literature. Eur J Endovasc Surg 2002, 23:283-294.

5. Schwartz LB, Bridgman AH, Kieffer RW, et al: Asymptomatic carotid artery stenosis and stroke in patients undergoing cardiopulmonary bypass. J Vasc Surg 1995, 21:146-153.

6. Roach GW, Kanchuger M, Mangano CM, et al: Adverse cerebral outcomes after coronary bypass surgery. N Engl J Med 1996, 335:1857-1863.

7. De Feo M, Renzulli A, Onorati F, et al: The risk of stroke following CABG: on possible strategy to reduce it? Int J Cardiol 2005, 98:261-266.

8. Salasidis GC, Latter DA, Steinmetz OK, et al: Carotid artery duplex scanning in preoperative assessment for coronary artery revascularization: the association between peripheral vascular disease, carotid artery stenosis, and stroke. J Vasc Surg 1995, 21:154-160.

9. D'Agostino RS, Svenson LG, Neumann DJ, et al: Screening carotid ultrasonography and risk factors for stroke in coronary artery surgery patients. Ann Thorac Surg 1996, 62:1714-1723.

10. Eagle KA, Guyton RA, Davidoff R, et al: ACC/AHA 2004 guideline update for coronary artery bypass graft surgery: a report of the American College of Cardiology/American Heart Association Task Force on Practice Guidelines. Circulation 2004, 110(14):e340-e437.

11. Grant EG, Benson CB, Moneta GL, et al: Carotid Artery Stenosis: Grayscale and Doppler Ultrasound Diagnosis-Society of Radiologists in Ultrasound Consensus Conference. Radiology 2003, 229:340-346.

12. Fukuda I, Gomi S, Watanabe K, et al: Carotid and aortic screening for coronary artery bypass grafting. Ann Thorac Surg 2000, 70:2034-2039.

13. Drohomirecka A, Kotowski L, Kwinecki P, et al: Risk factors for carotid artery disease in patients scheduled for coronary artery bypass grafting. Kardiol Pol 2010, 68:789-794.

14. Siminelakis $S$, Kotsanti $A$, Paziouros $C$, et al: Is there any difference in carotid stenosis between male and female patients undergoing coronary artery bypass grafting. Interact Cardiovasc Thorac Surg 2009, 9:823-826.

15. Venkatachalam S, Gray BH, Mukherjee D, Shisehbor MH: Contemporary management of concomitant carotid and coronary artery disease. Heart 2010, 97:175-180.

16. Mahmoudi M, Hill PC, Xue Z, et al: Patients with severe asymptomatic carotid artery stenosis do not have a higher risk of stroke and mortality after coronary artery bypass surgery. Stroke 2011, 42:2801-2805.

17. Durand DJ, Perler BA, Roseborough GS, et al: Mandatory versus selective preoperative carotid screening: a retrospective analysis. Ann Thorac Surg 2004, 78:159-166.

18. Li Y, Walicki D, Mathiesen C, et al: Strokes after cardiac surgery and relationship to carotid stenosis. Arch Neurol 2009, 66(9):1091-1096.

19. Sheiman RG, Bertrand JD: Screening carotid sonography before elective coronary artery bypass graft surgery: who needs it. AJR 2007, 188:475-479.

20. Fruchart JC, Nierman MC, Stroes ES, et al: New risk factors for atherosclerosis and patient risk assessment. Circulation 2004, 109(23 Suppl 1):III15-9.

21. Berens ES, Kouchoukos NT, Murphy SF, et al: Preoperative carotid artery screening in elderly patients undergoing cardiac surgery. J Vasc Surg 1992, 15:313-321.

doi:10.1186/1749-8090-7-78

Cite this article as: Wanamaker et al: Contemporary incidence and risk factors for carotid artery disease in patients referred for coronary artery bypass surgery. Journal of Cardiothoracic Surgery 2012 7:78. 